S1 Table TbALDH3 crystallography and refinement statistics

\begin{tabular}{lll}
\hline Dataset & 5MYP (wild type) & 5NNO (C259S) \\
Spacegroup & $P 1211$ & $P 1211$ \\
Wavelength $(\AA)$ & 1.54178 & 1.54178 \\
Resolution $(\AA)$ & $90.70-1.95(2.00-1.95)^{\mathrm{a}}$ & $46.56-2.50(2.60-2.50)^{\mathrm{a}}$ \\
Unit cell $(\AA)$ & 87.7263 .9591 .75 & 89.1762 .5292 .97 \\
Unique reflections & $72557(4318)$ & $34306(3730)$ \\
Completeness $(\%)$ & $99.4(95.9)$ & $97.6(93.9)$ \\
$<I / s(I)>$ & $10.1(3.8)$ & $12.9(8.0)$ \\
Multiplicity & $4.9(3.5)$ & $3.1(2.6)$ \\
$R_{\text {merge }}$ & $0.099(0.213)$ & $0.074(0.112)$ \\
$R_{\text {meas }}$ & $0.111(0.250)$ & $0.090(0.138)$ \\
$C C(1 / 2)$ & $0.993(0.941)$ & $0.989(0.968)$
\end{tabular}

\title{
Refined model
}

\begin{tabular}{lll}
\hline$R_{\text {work }}{ }^{c}$ & 0.20 & 0.24 \\
$R_{\text {free }}{ }^{d}$ & 0.22 & 0.28 \\
Protein residues & 973 & 978 \\
Other components & $\begin{array}{l}520 \text { water, } \\
1 \text { glycerol }\end{array}$ & 200 water, 2 NAD, \\
& & \\
rmsd from ideal geometry & 0.007 & 0.011 \\
$\begin{array}{l}\text { bond lengths }(\AA) \\
\text { bond angles }\left(^{\circ}\right)\end{array}$ & 1.01 & 1.55 \\
$\begin{array}{l}\text { Thermal parameter }(B) \text { values } \\
\left(\AA^{2}\right)\end{array}$ & & \\
$\begin{array}{l}\text { From Wilson plot } \\
\text { Mean } B \text { over all atoms }\end{array}$ & 14.8 & 10.8 \\
$\begin{array}{l}\text { Mean } B \text { over all atoms for } \\
\text { protein/waters/NAD/AN3057 } \\
\text { aldehyde }\end{array}$ & 19.0 & 11.6 \\
\hline
\end{tabular}

\begin{tabular}{lll}
\hline Ramachandran & $98.2 / 1.2 / 0.4$ & $97.5 / 2.3 / 0.2$
\end{tabular}

favoured/allowed/outliers (\%)

a. Values in parentheses refer to the highest resolution bin; b. $R_{\text {merge }}=\sum h \sum i \|(h, i)-<1(h)>$ $\sum h \sum i \mid(h, i)$; c. $R_{\text {work }}=\sum h k\left\||| F_{o}|-| F_{c}\right\| /\left|\sum\right| F_{o} \mid$, where $F_{o}$ is the observed structure factor amplitude and the $F_{c}$ is the structure-factor amplitude calculated from the model; $\boldsymbol{d}$. $R_{\text {free }}$ is the same as $R_{\text {work }}$ except only calculated using a subset, $5 \%$, of the data that are not included in any refinement calculations. 